\section{BMJ Open Respiratory Research}

\title{
Prompt recognition of infectious pulmonary tuberculosis is critical to achieving elimination goals: a retrospective cohort study
}

\author{
Courtney Heffernan (D , 1 James Barrie, ${ }^{2}$ Alexander Doroshenko, ${ }^{3}$ \\ Mary Lou Egedahl, ${ }^{1}$ Catherine Paulsen, ${ }^{1}$ Ambikaipakan Senthilselvan, ${ }^{4}$ \\ Richard Long ${ }^{1}$
}

To cite: Heffernan C, Barrie J, Doroshenko A, et al. Prompt recognition of infectious pulmonary tuberculosis is critical to achieving elimination goals: a retrospective cohort study. BMJ Open Resp Res 2020;7:e000521. doi:10.1136/ bmjresp-2019-000521

- Additional material is published online only. To view please visit the journal online (http://dx.doi.org/10.1136/ bmjresp-2019-000521).

Received 29 October 2019

Revised 16 April 2020

Accepted 29 April 2020

Check for updates

C Author(s) (or their employer(s)) 2020. Re-use permitted under CC BY-NC. No commercial re-use. See rights and permissions. Published by BMJ.

${ }^{1}$ Department of Medicine; Division of Pulmonary Medicine, University of Alberta, Edmonton, Alberta, Canada

${ }^{2}$ Department of Radiology and Diagnostic Imaging, University of Alberta, Edmonton, Alberta, Canada

${ }^{3}$ Department of Medicine; Division of Preventive Medicine, University of Alberta, Edmonton, Alberta, Canada

${ }^{4}$ School of Public Health, University of Alberta, Edmonton, Alberta, Canada

Correspondence to Dr Richard Long; rlong@ualberta.ca

\section{ABSTRACT}

Introduction All pulmonary tuberculosis (PTB) cases are presumed to be infectious to some degree. This spectrum of infectiousness is independently described by both the acidfast bacilli smear and radiographic findings. Smear-positive patients with chest radiographic findings that are typical for adult-type PTB are believed to be most infectious.

Hypothesis Characterisation of the presumed most infectious PTB case is possible by reference to readily available clinical features and laboratory results.

Methods Retrospective cohort study of adult, culturepositive PTB cases (151 smear-positive; 162 smear-negative) diagnosed between 1 January 2013 and 30 April 2017 in Canada. We describe cases according to demographic, clinical and laboratory features. We use multivariable multinomial logistic regression to estimate the relative risk ratio (RRR) with $95 \% \mathrm{Cl}$ of features associated with an outcome of smear-positive PTB, characterised by 'typical' chest radiograph findings.

Results Being Canadian-born, symptomatic, having a subacute duration of symptoms and broad-spectrum antibiotic prescriptions were all more commonly associated with smear-positive than smear-negative disease (36\% vs $20 \%$; $95 \%$ vs $63 \%$; $88 \%$ vs $54 \%$; and $59 \%$ vs $28 \%$, respectively). After combining smear status and radiographic features, we show that smear-positive patients with typical chest radiographs were younger, had a longer duration of symptoms (RRR 2.41; 95\% $\mathrm{Cl} 1.01$ to 5.74 and 2.93; $95 \% \mathrm{Cl}$ 1.20 to 7.11 , respectively) and were less likely to be foreignborn, or have a moderate to high-risk factor for reactivation (RRR 0.40; $95 \% \mathrm{Cl} 0.17$ to 0.92 and $0.18 ; 95 \% \mathrm{Cl} 0.04$ to 0.71 , respectively) compared with smear-negative patients with atypical chest radiograph findings.

Conclusion A clear picture of the presumed most infectious PTB case emerges from available historical and laboratory information; vigilance for this presentation by front-line providers will support elimination strategies aimed at reducing transmission.

\section{INTRODUCTION}

Elimination of tuberculosis (TB) requires a dual-pronged approach. Both interrupting transmission by promptly diagnosing and

\section{Key messages}

What is the key question?

- Can we identify a highly infectious pulmonary tuberculosis (TB) case in high-income, low-TB incidence settings?

What is the bottom line?

- A combination of readily available clinical $(n=6)$ and laboratory $(\mathrm{n}=2)$ features describes the prototypical infectious case of pulmonary TB.

\section{Why read on?}

- The timely diagnosis of infection-spreading cases, especially by front-line providers, is critical to interrupting transmission, and thus, to meeting TB elimination targets.

treating infection-spreading cases, and preventing TB among those already infected but who have not yet developed a disease are necessary. As TB becomes less common in high-income, low-incidence settings, the prompt diagnosis of infection-spreading cases by front-line physicians and nurses becomes increasingly difficult. These cases are mainly bacillary positive (smear-positive, culturepositive and smear-negative, culture-positive) pulmonary TB (hereafter 'PTB'). Among culture-positive PTB cases, those with smearpositive disease are 5-10 times more likely to generate a secondary case than those who are smear-negative. ${ }^{1-3}$ In addition, among persons with smear-positive PTB, those with 'typical' findings on chest radiograph (defined below) are 10 times more likely to generate a secondary case than smearpositive cases without such features. ${ }^{4}$ Thus, both the smear status and the presentation of disease on chest radiograph contribute independently to transmission. ${ }^{4-7}$ 
Six features from the medical history and two readily available laboratory tests (the chest radiograph and complete blood count (CBC)) have emerged, both within the literature and clinical practice, as being critical to suspecting PTB rather than disease attributable to other respiratory pathogens, and subsequently ordering the collection of sputum or other specimens for mycobacteriological examination. ${ }^{8} 9$ The relative predictive value of each variable on an outcome of PTB in a specialised TB clinic has previously been shown. ${ }^{10}$ What has not been shown is how well the combination of these features differentiates the highly infectious case from the minimally infectious case, among whom the collection of a sputum is imperative for achieving public health goals.

The objective of this current study is to distinguish smear-positive and smear-negative PTB by describing the relative frequency of the aforementioned features in a well-defined cohort of adult patients. While all patients with PTB are presumed infectious to some degree, it is the smear-positive case with typical chest radiographic findings whose timely diagnosis offers the greatest potential for interrupting transmission, and impacting public health. Meeting this objective could establish a clinical threshold for front-line providers to consider the diagnosis and seek subsequent laboratory confirmation, which is important to TB elimination efforts. ${ }^{11}$

\section{METHODS}

This study was performed in Alberta-population over 4.25 million in 2016 (Statistics Canada)-one of four major immigrant-receiving provinces in Canada, the other three being British Columbia, Ontario and Quebec. In Alberta, in 2016, the crude incidence rate of TB was 5.6 per 100000 population. University-based pulmonary and infectious disease physicians staff three dedicated public health clinics that provide TB services to the province. ${ }^{9}$ Language line (translation) services are available as necessary. Introduction of an assessment form into the two clinics supported by University of Alberta staff occurred in 2013. It records relevant information for each referred case. We identified a cohort of consecutive, adult (age $>14$ years), culture-positive pulmonary cases diagnosed between 1 January 2013 and 30 April 2017 from these two clinics. We supplemented data collected through the assessment form with findings from the Provincial Laboratory for Public Health, which performs all mycobacteriology in the province. Per standard of care, patients whose initial sputum specimens were smear-negative had three additional specimens collected at the time of reporting of the first positive culture to confirm that they were still smear-negative on the start date of treatment, which, in Alberta, is the date of diagnosis. The initial isolate of each case was genotyped using mycobacterial interspersed repetitive units, and laboratory cross-contamination was excluded in all patients with a single, smear-negative, culture-positive specimen. ${ }^{12}$
Basic demographic and clinical information is used to describe the cohort of patients in this study. These data included: age at diagnosis (15-64 years, $>64$ years), sex, population group (Canadian born and foreign born), disease type (new active vs relapse/retreatment) and HIV status (positive, negative). We then examined the following eight explanatory variables, which we hypothesise describe the most infectious case of PTB.

Clinical characteristics included, as above, six pieces of information related to patient histories: (1) symptoms, (2) duration of symptoms, (3) absence of dyspnoea, (4) broad-spectrum antibiotic prescriptions in the 6 months antedating diagnosis, (5) epidemiological risk of exposure to, or infection with, Mycobacterium tuberculosis, and (6) risk factors for the reactivation of latent TB infection (LTBI). Symptoms, if present, were reported as respiratory (dry cough, productive cough, haemoptysis or chest pain), constitutional (fever, night sweats, weight loss or fatigue) or both. ${ }^{13}$ The absence of dyspnoea is known to favour a diagnosis of PTB over community-acquired pneumonia; parallel reductions in ventilation and perfusion at sites of PTB disease are known to preserve gas exchange. ${ }^{14-16}$ We documented antibiotic prescriptions in individual records, and confirmed their prescription for respiratory complaints by cross-referencing the cohort against the provincial (Alberta Health) stakeholder registry, which, in turn, reports physician claims for the reimbursement of services provided.

Epidemiological risks include: a history of $\mathrm{TB}$, and whether it was adequately treated, a history of overt contact with PTB, and whether it was adequately assessed (eg, tuberculin skin test or interferon gamma release assay) and treated, migration from a high-incidence country of birth, or travel and work to/within a high-incidence country, an occupational history (eg, healthcare worker), and/or social risk factors such as homelessness, incarceration and alcohol/substance misuse where non-overt exposures might occur. Online supplementary table 1 provides a description of social factors including homelessness, incarceration and alcohol/substance misuse. We reported the presence or absence of one or more 'moderate' or 'high risk' factors for the reactivation of LTBI, as described in the Canadian Tuberculosis Standards. ${ }^{17}$ Finally, we report the results of two routine laboratory tests performed at the time of diagnosis: the $\mathrm{CBC}$ and the chest radiograph. The results of the CBC are grouped into four patterns based on the presence or absence of anaemia, and/or leucocytosis. ${ }^{18} 19$

An experienced chest radiologist, blind to the smear status of the patients, re-read the posterior-anterior and lateral chest images performed at the time of diagnosis. In the context of this study, $d$ frontal images were divided into four quadrants by halving a perpendicular drawn from the apex of the lung to the dome of the hemidiaphragm. Documented were the presence or absence of (1) parenchymal infiltrates and their dominant location-no distinction was made between infiltrates that were airspace, interstitial, nodular or some combination 
of these; (2) cavities, defined as a gas-filled space within pulmonary consolidation, a mass, or a nodule; (3) adenopathy—hilar, mediastinal or both; and (4) pleural effusion.

As previously reported, we categorised patients as having 'typical' versus 'atypical' radiographs based on the characteristics listed above. ${ }^{420}$ For patients with infiltration localised to, or predominantly in the upper long zones, with or without cavitation, but with no discernable intrathoracic adenopathy, the radiograph is 'typical' for adult-type PTB. In patients with (1) no abnormality; (2) intrathoracic adenopathy with or without parenchymal disease; (3) a localised or predominant lower lung zone infiltrate, with or without cavitation; (4) an isolated pleural effusion; and (5) a miliary (diffuse micronodular) pattern, the radiograph is 'atypical' for adult-type PTB. We report extent of disease on chest radiograph as normal, minimal, moderately, far advanced or miliary according to criteria established by the US National Tuberculosis and Respiratory Disease Association. ${ }^{21}$

\section{Statistical analysis}

We describe cases by smear status according to each of the aforementioned features. We tested the difference in proportions, by smear status, of each feature between two independent samples using the direct test, Fisher's exact test or $\chi^{2}$ test as appropriate. Thereafter, we generated a combined outcome of smear status and radiographic findings, creating an outcome for multinomial logistic regression that was a nominal variable with four responses: atypical smear-negative, typical smear-negative, atypical smear-positive and typical smear-positive, with atypical smear-negative considered to be the baseline group. The model includes all features and confounders considered clinically relevant to making a timely diagnosis of $\mathrm{TB}$ from a review of the literature. The total sample size of 313 in this study achieves $80 \%$ power or greater to detect an effect size (W) of 0.19 or greater for comparison of proportions between four groups using $3 \mathrm{df}$, and $\chi^{2}$ test with a significance level (alpha) of $0.05 .{ }^{22}$ We performed all statistical analyses using STATA V.14, StataCorp 2015. There were no missing data within this cohort.

\section{Patient and public involvement}

We did not involve patients and the public in this study given its retrospective design, but we anticipate that the findings presented herein will lead to benefits for future cohorts of patients.

\section{RESULTS}

There were 313 patients in the cohort, 151 (48\%) smearpositive and 162 (52\%) smear-negative. Being Canadianborn was associated with a greater likelihood of having smear-positive than smear-negative disease $(36 \%$ vs $20 \%$ ); otherwise there were no statistically significant differences in the age, sex, disease type,or HIV status between these two groups (see table 1). The leading countries of birth of foreign-born patients were the Philippines (38\%), India (16\%), Vietnam (5\%) and Somalia (5\%); Bhutan, Ethiopia and China each contributed 3\% of foreign-born patients.

As shown in table 2, being symptomatic with either respiratory, constitutional or both types of symptoms at the time of diagnosis was more likely in smear-positive than smear-negative patients (95\% vs 63\%). Cough (dry or productive) and haemoptysis were more common in smear-positive than smear-negative patients ( $83 \%$ vs $45 \%$, and $25 \%$ vs $6 \%$, respectively). Chest pain was equally uncommon in both groups (11\% vs $9 \%)$. Dyspnoea was also relatively uncommon in both groups (28\% vs $14 \%$ ). Each of the major constitutional symptoms was more common in smear-positive than smear-negative patients (weight loss, $50 \%$ vs 28\%; fever, $45 \%$ vs $20 \%$; night sweats, $24 \%$ vs $10 \%$; and fatigue, $21 \%$ vs $12 \%$ ). Finally, having a combination of respiratory and constitutional symptoms ( $70 \%$ vs $28 \%$ ) and a duration of symptoms $\geq 2$ weeks $(88 \%$ vs $54 \%)$ were statistically significantly more common in smear-positive than smear-negative patients. Among smear-positive and smear-negative patients with any symptoms, $93 \%$ and $86 \%$, respectively, had symptoms for $\geq 2$ weeks (data not shown).

We dichotomised possible combinations of antibiotic prescription, epidemiological risk and reactivation risk, and describe their associations with an outcome of either smear-positive or smear-negative disease (table 3). A history of broad-spectrum antibiotic prescription for a respiratory complaint in the 6 months preceding the date of diagnosis was more likely among smear-positive patients (57\% vs 23\%); of those, multiple prescriptions were also more likely among smear-positive patients (49\% vs $36 \%$-data not shown). Macrolides, penicillins and fluoroquinolones were, in order of frequency, the three major classes of antibiotics prescribed. If one assumes that antibiotic prescriptions for respiratory complaints, in the months immediately preceding their diagnosis, were due to PTB then there were missed opportunities to diagnose these patients. In absolute numbers, there were 291 antibiotic prescriptions in the 6 months antedating a TB diagnosis; 208 among persons ultimately diagnosed with smear-positive PTB and 83 among persons ultimately diagnosed with smear-negative PTB (data not shown).

Almost all patients in both groups (95\%) had some epidemiological risk. The distribution of social risk factors was similar in smear-positive and smear-negative patients. Notably, however, they were much more common among Canadian-born than among foreign-born patients (see online supplementary table 1). A moderate to high risk of reactivation was similarly uncommon in both smearpositive and smear-negative patients (6\% vs $9 \%)$.

Anaemia was more common in smear-positive than smear-negative cases ( $65 \%$ vs $42 \%$ ). Anaemia was usually of the chronic disease, iron deficiency varieties or both (data not shown). A leucocytosis was uncommon in both groups, but more uncommon in smear-negative cases 
Table 1 Demographic and clinical characteristics of patients with pulmonary tuberculosis by smear status

\begin{tabular}{|c|c|c|c|c|}
\hline \multirow[b]{2}{*}{ Characteristics } & \multirow[b]{2}{*}{$\begin{array}{l}\text { Total } \\
\mathbf{n}\end{array}$} & \multicolumn{2}{|c|}{ Smear status* } & \multirow[b]{2}{*}{$P$ value $\neq$} \\
\hline & & $\begin{array}{l}\text { Positive } \\
\text { n (\%) }\end{array}$ & $\begin{array}{l}\text { Negative } \\
\text { n (\%) }\end{array}$ & \\
\hline Assessed, $n$ & 313 & 151 & 162 & \\
\hline \multicolumn{5}{|l|}{ Age } \\
\hline $15-64$ years & 248 & $120(79.4)$ & $128(79.0)$ & 0.38 \\
\hline$>64$ years & 65 & $31(20.6)$ & $34(21.0)$ & \\
\hline \multicolumn{5}{|l|}{ Sex } \\
\hline Male & 173 & $86(57.0)$ & $87(53.8)$ & 0.56 \\
\hline Female & 140 & $65(43.0)$ & 75 (46.2) & \\
\hline \multicolumn{5}{|l|}{ Population group $†$} \\
\hline Foreign-born & 226 & 97 (64.3) & $129(79.7)$ & 0.002 \\
\hline Canadian-born & 87 & $54(35.7)$ & $33(20.3)$ & \\
\hline \multicolumn{5}{|l|}{ Disease type } \\
\hline New active & 280 & $135(89.4)$ & $145(89.5)$ & 0.97 \\
\hline Relapse/retreatment & 33 & $16(10.6)$ & 17 (10.5) & \\
\hline \multicolumn{5}{|l|}{ HIV status } \\
\hline Negative & 300 & $147(97.4)$ & $153(94.5)$ & 0.19 \\
\hline Positive & 13 & $4(2.6)$ & $9(5.5)$ & \\
\hline
\end{tabular}

*Smear-positive patients had to have one or more airway secretion specimens, on or before the start date of treatment, with a semiquantitative smear size of $1+$ or greater.

†Canadian-born includes 61 indigenous patients and 26 Canadian-born non-indigenous patients. Among the foreign-born patients, one smear-positive and 28 smear-negative were referred to public health through the immigration medical screening surveillance mechanism. ‡Difference in proportions [(smear-positive)-(smear-negative)]; sample size was adequate to detect observable differences.

(21\% and $7 \%)$. The mean and median haemoglobin in smear-positive males and females was 127 and $126 \mathrm{~g} / \mathrm{L}$, and 112 and $112 \mathrm{~g} / \mathrm{L}$, respectively. In smear-negative males and females, it was 135 and $142 \mathrm{~g} / \mathrm{L}$, and 123 and $124 \mathrm{~g} / \mathrm{L}$, respectively. The mean and median leucocyte count was $8.6 \times 10^{9} / \mathrm{L}$ and $7.8 \times 10^{9} / \mathrm{L}$ in smear-positive cases, and $7 \times 10^{9} / \mathrm{L}$ and $7 \times 10^{9} / \mathrm{L}$ in smear-negative cases. The reference range for a normal haemoglobin is $135-175 \mathrm{~g} / \mathrm{L}$ and $120-160 \mathrm{~g} / \mathrm{L}$ for males and females, respectively. The reference range for a normal leucocyte count is $4.0-11.0 \times 10^{9} / \mathrm{L}$.

Chest radiographic features that are 'typical' for adulttype PTB, bilateral disease, cavitation and moderate or far-advanced disease were all more common in smearpositive than smear-negative patients (78\% vs 36\%; $56 \%$ vs $21 \%$; $62 \%$ vs $6 \%$; and $81 \%$ vs $22 \%$, respectively). Among smear-positive patients, those with cavitation had a statistically significantly higher semiquantitative smear grade $(3+$ to $4+)$ vs $(1+$ to $2+), 82 \%$ vs $46 \%$ than those without cavitation (data not shown). Only three patients, one smear positive and two smear negative, had a miliary pattern.

Table 4 shows the findings of our multinomial logistic regression. An absence of dyspnoea was more likely among smear-negative patients with typical chest radiograph findings than smear-negative patients with atypical chest radiograph findings; lower lung zone disease and dependent effusions-atypical findings on chest radiograph-are presumed to more negatively affect gas exchange (relative risk ratio (RRR) $4.71,95 \%$ CI 1.69 to 13.18). Young age and a subacute or chronic duration of symptoms were more greatly associated with smearpositive patients who have typical chest radiographs than smear-negative patients with atypical chest radiographs (RRR 2.41; 95\% CI 1.01 to 5.74, and RRR 2.93; 95\% CI 1.20 to 7.11, respectively), while being foreign born and having a moderate to high-risk factor for reactivation were less commonly associated with smear-positive PTB with typical chest radiographs than smear-negative patients with PTB with atypical chest radiographs (RRR $0.40 ; 95 \%$ CI 0.17 to 0.92 , and RRR 0.18 ; $95 \%$ CI 0.04 to 0.71 , respectively) (see table 4 and online supplementary table 2). All major symptoms, respiratory and constitutional, were more commonly associated with typical presentation, cavitation, bilateral and moderate to advanced disease on chest radiograph (see online supplementary table 3 ).

\section{DISCUSSION}

It has previously been established that of the information readily available to front-line providers, three pieces are key to triggering suspicion of PTB. These include symptoms, especially if both respiratory and constitutional and subacute or chronic, and typical chest radiographic features; a public health trigger is an epidemiological 
Table 2 Symptoms and their duration in patients with pulmonary tuberculosis by smear status

\begin{tabular}{|c|c|c|c|c|}
\hline \multirow[b]{2}{*}{ Characteristics } & \multirow[b]{2}{*}{$\begin{array}{l}\text { Total } \\
\mathbf{n}\end{array}$} & \multicolumn{2}{|c|}{ Smear status } & \multirow[b]{2}{*}{ P value $^{*}$} \\
\hline & & $\begin{array}{l}\text { Positive } \\
\text { n (\%) }\end{array}$ & $\begin{array}{l}\text { Negative } \\
\text { n (\%) }\end{array}$ & \\
\hline Assessed, $\mathrm{n}$ & 313 & 151 & 162 & - \\
\hline \multicolumn{5}{|l|}{ Symptomatic } \\
\hline Yes & 245 & $143(94.7)$ & $102(63.0)$ & \multirow[t]{2}{*}{$<0.001$} \\
\hline No & 68 & $8(5.3)$ & $60(37.0)$ & \\
\hline \multicolumn{5}{|l|}{ Symptoms } \\
\hline Respiratory & 217 & $133(88.1)$ & $84(51.8)$ & \multirow[t]{5}{*}{$<0.001$} \\
\hline Cough (dry) & 149 & $90(59.6)$ & $59(36.4)$ & \\
\hline Cough (productive) & 50 & $36(23.8)$ & $14(8.6)$ & \\
\hline Haemoptysis & 46 & $37(24.5)$ & $9(5.5)$ & \\
\hline Chest pain & 31 & $17(11.2)$ & $14(8.6)$ & \\
\hline \multicolumn{5}{|l|}{ Absence of dyspnoea } \\
\hline Yes & 249 & 109 (72.2) & $140(86.4)$ & \multirow[t]{2}{*}{$<0.001$} \\
\hline No & 64 & $42(27.8)$ & $22(13.6)$ & \\
\hline Constitutional & 176 & $113(74.8)$ & $63(38.8)$ & $<0.001$ \\
\hline Weight loss & 121 & $76(50.3)$ & $45(27.7)$ & \\
\hline Fever & 101 & $68(45.0)$ & $33(20.3)$ & \\
\hline Night sweats & 52 & $36(23.8)$ & $16(9.8)$ & \\
\hline Fatigue & 51 & $31(20.5)$ & 20 (12.3) & \\
\hline \multicolumn{5}{|l|}{ Both† } \\
\hline Yes & 151 & 105 (69.5) & $46(28.4)$ & \multirow[t]{2}{*}{$<0.001$} \\
\hline No & 162 & $46(30.5)$ & $116(71.6)$ & \\
\hline \multicolumn{5}{|l|}{ Duration of symptoms } \\
\hline$\geq 2$ weeks & 221 & $133(88.0)$ & $88(54.3)$ & \multirow[t]{2}{*}{$<0.001$} \\
\hline$<2$ weeks & 92 & 18 (12.0) & $74(45.7)$ & \\
\hline
\end{tabular}

${ }^{*}$ Difference in proportions [(smear-positive)-(smear-negative)]; sample size was adequate to detect observable differences.

†Patients with some combination of both respiratory and constitutional symptoms.

risk of having or acquiring LTBI (see figure 1). Our study shows that although a public health risk was similarly common in smear-positive and smear-negative cases $(95 \%$ and $97 \%$, respectively), clinical triggers (symptoms: $95 \%$ vs $63 \%$, and typical chest radiographic features: $78 \%$ vs $36 \%$ ) were much more common in smear-positive cases; fortuitous given that smear positivity and typical radiographic features are presently the major determinants of infectiousness, and therefore the public health risk PTB poses. ${ }^{1-4} 7$ Other variables, including broad-spectrum antibiotic prescription history, reactivation risk factors and the CBC findings, are supportive in considering the likelihood of PTB.

Individually, each of the features identified in the multinomial logistic regression model as distinguishing (typical) smear-positive cases from (atypical) smearnegative cases has precedent in the literature, including younger age ${ }^{2324}$; symptoms and their duration ${ }^{25-27}$; less likely to be foreign-born ${ }^{14}$; ; and less likely to have a moderate to high-risk factor for reactivation. ${ }^{29-32}$ When combined, the features have utility for describing the prototypical smear-positive patient with typical chest radiographic features: a young middle-aged man or woman with an epidemiological risk for LTBI, and a subacute or chronic duration of symptoms, a history of broad-spectrum antibiotic prescriptions, rarely having a risk factor for reactivation, and with an anaemia and a normal or low leucocyte count on CBC.

In the future, semiquantitative results from the real-time PCR method, Xpert MTB/RIF assay, may replace smear microscopy and its current role as a proximate measure of infectiousness. ${ }^{33}{ }^{34}$ There is, however, no expectation that this technology will impact the picture of the prototypical infectious case described herein. By contrast, cough aerosol technology might. For reasons that are only speculative at this time, some patients, whether smear positive or smear negative, are better able to generate an infectious aerosol than others. ${ }^{35}$ Therefore, once available, this technology is expected to further clarify the picture of the most infectious cases. The earlier the detection of these cases, the lesser the transmission and the smaller the reservoir of LTBI, the seedbed of future cases. 
Table 3 Broad-spectrum antibiotic use, epidemiological risk, reactivation risk and laboratory features in patients with pulmonary tuberculosis by smear status

\begin{tabular}{|c|c|c|c|c|}
\hline \multirow[b]{2}{*}{ Characteristics } & \multirow[b]{2}{*}{$\begin{array}{l}\text { Total } \\
\mathrm{n}\end{array}$} & \multicolumn{2}{|c|}{ Smear status } & \multirow[b]{2}{*}{ P value* } \\
\hline & & $\begin{array}{l}\text { Positive } \\
\text { n (\%) }\end{array}$ & $\begin{array}{l}\text { Negative } \\
\text { n (\%) }\end{array}$ & \\
\hline Assessed, $\mathrm{n}$ & 313 & 151 & 162 & - \\
\hline \multicolumn{5}{|l|}{ Antibiotic use $†$} \\
\hline Yes & 124 & $86(56.9)$ & $38(23.5)$ & \multirow[t]{2}{*}{$<0.001$} \\
\hline No & 189 & $65(43.1)$ & $124(76.5)$ & \\
\hline \multicolumn{5}{|l|}{ Epidemiological risk $\ddagger$} \\
\hline Yes & 301 & $144(95.4)$ & $157(96.9)$ & \multirow[t]{2}{*}{0.48} \\
\hline No & 12 & $7(4.3)$ & $5(3.1)$ & \\
\hline \multicolumn{5}{|l|}{ Reactivation risk§ } \\
\hline Yes & 23 & $9(5.9)$ & $14(8.6)$ & \multirow[t]{2}{*}{0.35} \\
\hline No & 290 & $142(94.1)$ & $148(91.4)$ & \\
\hline \multicolumn{5}{|l|}{ Complete blood count } \\
\hline Normal haemoglobin; leucocytosis ${ }^{\star *}$ & 8 & $7(4.6)$ & $1(0.6)$ & 0.03 \\
\hline Normal haemoglobin; normal/low leucocyte count & 139 & $46(30.4)$ & $93(57.4)$ & $<0.001$ \\
\hline Anaemia and leucocytosis ${ }^{* \star}$ & 36 & $25(16.5)$ & $11(6.7)$ & 0.01 \\
\hline Anaemia and normal/low leucocyte count & 130 & $73(48.5)$ & $57(35.3)$ & 0.01 \\
\hline \multicolumn{5}{|l|}{ Chest radiographs } \\
\hline Typical appearance†† & 176 & $118(78.1)$ & $58(35.8)$ & $<0.001$ \\
\hline Bilateralł‡ & 118 & $84(55.6)$ & $34(21.1)$ & $<0.001$ \\
\hline Cavitary & 103 & $93(61.5)$ & $10(6.1)$ & $<0.001$ \\
\hline Extent: moderate to far-advanced disease§§ & 159 & $123(81.4)$ & $36(22.2)$ & $<0.001$ \\
\hline
\end{tabular}

*Difference in proportions [(smear-positive)-(smear-negative)]; sample size was adequate to detect observable differences.

†Refers to broad-spectrum antibiotic use in the 6 months preceding the date of diagnosis (the start date of treatment).

$\ddagger$ Epidemiological risk for exposure to Mycobacterium tuberculosis.

§Moderate to high-risk factors for the reactivation of tuberculosis in those with latent tuberculosis (TB) infection, according to the Canadian Tuberculosis Standards.

१TThe reference range for a normal haemoglobin is $135-175 \mathrm{~g} / \mathrm{L}$ and $120-160 \mathrm{~g} / \mathrm{L}$ for males and females, respectively. The reference range for a normal leucocyte count is $4.0-11.0 \times 10^{9} / \mathrm{L}$. Anaemia and leucocytosis among smear-positive cases as compared with smear-negative cases $(65 \%$ vs $42 \%$ and $21 \%$ vs $7 \%)$ were significant at $p \leq 0.05$, using Pearson's $\chi^{2}$ test.

${ }^{\star *}$ Fisher's exact test and $\chi^{2}$ test used to test for differences.

††Typical=upper lung zone predominant infiltrate, with or without cavitation, but no discernable adenopathy.

$\ddagger \ddagger$ Of the 176 cases without bilateral disease, 27 had a normal chest X-ray (CXR): 25 smear negative and 2 smear positive. One of the 25

smear-negative cases with a 'normal' CXR had evidence of intrathoracic adenopathy and normal-appearing lung parenchyma.

$\S \S$ Includes three cases with a miliary pattern (see text).

It is a common misconception that smear-negative disease is early disease, and smear-positive disease is late disease and that the extent of disease on chest radiograph is an indication of its duration, that is, that a minimal lesion is early disease and a moderate or advanced lesion is old or chronic disease. Years ago, Kurt Toman used data from longitudinal studies, and periodic X-ray surveys of large populations to dispel this idea. ${ }^{27} \mathrm{He}$ concluded that both types of disease-advanced smear-positive TB and minimal, only culture-positive $\mathrm{TB}$ - usually developed within the same time frame; thus, making a diagnosis at first presentation an important piece of the elimination puzzle. A recent proof-of-concept study supports his findings of different phenotypic expressions of disease. ${ }^{20}$ The proportion of smear-positive and smear-negative patients in our study that were asymptomatic (5\% and 37\%, respectively) is remarkably similar to what he reported across diverse ethnic groups many years ago. ${ }^{36-38}$

The strengths of this study include the completeness of the data, made possible by the use of an assessment form and the centralised nature of the programme, and the validation of key variables, for example, the attribution of smear status, radiographic features and broad-spectrum antibiotic prescriptions. Consecutive patients in the jurisdiction and time period of the study were included. This may be considered both a strength (reflecting programmatic realities and an unfiltered comparison of smearpositive and smear-negative disease) and a weakness (the pathway to diagnosis in smear-negative cases may be through active vs passive case finding activities such as 
Table 4 Multivariable multinomial regression showing the associations between demographic and clinical characteristics to a combined smear, and radiographic outcome

\begin{tabular}{|c|c|c|c|c|c|c|c|}
\hline \multirow{2}{*}{$\begin{array}{l}\text { Demographic } \\
\text { and clinical } \\
\text { characteristics }\end{array}$} & \multicolumn{3}{|c|}{ Smear negative } & \multicolumn{4}{|c|}{ Smear positive } \\
\hline & $\begin{array}{l}\begin{array}{l}\text { Atypical } \\
\text { (base) }\end{array} \\
\mathrm{n}(\%)\end{array}$ & \multicolumn{2}{|l|}{ Typical } & \multicolumn{2}{|l|}{ Atypical } & \multicolumn{2}{|l|}{ Typical } \\
\hline Assessed, $\mathrm{n}$ & 51 & 111 & & 33 & & 118 & \\
\hline \multicolumn{8}{|l|}{ Age (years) } \\
\hline \multicolumn{8}{|l|}{ Sex } \\
\hline Female & $22(15.7)$ & $53(37.9)$ & 1.00 & $13(9.3)$ & 1.00 & $52(37.1)$ & 1.00 \\
\hline Male & $29(16.8)$ & $58(33.5)$ & 0.77 (0.38 to 1.56$)$ & $20(11.6)$ & 1.15 (0.45 to 2.93$)$ & $66(38.2)$ & 0.90 (0.44 to 1.83$)$ \\
\hline \multicolumn{8}{|l|}{ Population group } \\
\hline No & $15(23.4)$ & $7(11.0)$ & 1.00 & $16(25.0)$ & 1.00 & $26(40.6)$ & 1.00 \\
\hline Yes & $36(14.4)$ & $104(41.8)$ & 4.71 (1.69 to 13.18$)$ & $17(6.8)$ & 0.59 (0.22 to 1.60$)$ & $92(37.0)$ & 1.85 (0.79 to 4.34$)$ \\
\hline \multicolumn{8}{|c|}{ Duration of symptoms ${ }^{*}$} \\
\hline$<2$ weeks & $18(19.5)$ & $56(60.9)$ & 1.00 & $3(3.3)$ & 1.00 & $15(16.3)$ & 1.00 \\
\hline$\geq 2$ weeks & $33(14.9)$ & 55 (24.9) & 0.68 (0.31 to 1.75$)$ & $30(13.6)$ & 3.86 (0.93 to 15.92$)$ & $103(46.6)$ & $2.93(1.20$ to 7.11$)$ \\
\hline \multicolumn{8}{|l|}{ Antibiotics } \\
\hline No & 35 (18.5) & $89(47.1)$ & 1.00 & $13(6.9)$ & 1.00 & $52(27.5)$ & 1.00 \\
\hline Yesł & $16(12.9)$ & $22(17.7)$ & $0.74(0.31$ to 1.75$)$ & $20(16.1)$ & 2.14 (0.79 to 5.82$)$ & $66(53.2)$ & 1.76 (0.79 to 3.89$)$ \\
\hline \multicolumn{8}{|l|}{ Epidemiological risk§ } \\
\hline Low risk & $5(11.4)$ & 7 (15.9) & 1.00 & 5 (11.4) & 1.00 & $27(61.4)$ & 1.00 \\
\hline High risk & $46(17.1)$ & $104(38.7)$ & 1.26 (0.36 to 3.28$)$ & $28(10.4)$ & 0.64 (0.15 to 2.61$)$ & $91(33.8)$ & $0.49(0.16$ to 1.48$)$ \\
\hline
\end{tabular}

'The presence of 'symptoms' and the 'duration of symptoms' were considered collinear-here we report just on the duration of symptoms.

†One or more broad-spectrum antibiotics prescribed in the 6 months prior to diagnosis.

$\ddagger$ One or more broad-spectrum antibiotic prescription(s) within six months of the PTB diagnosis with no, or a limited and unsustained

therapeuticbenefit.

§Epidemiological risks none/low=no known occupational risk, travel history, migration from endemic nation, place of residence in a high-incidence indigenous community, recent contact with a known TB case plus no history of TB; OR, a history of TB/latent TB infection (LTBI) that has been adequately treated. Moderate to high=occupational risk, travel history, migration from endemic nation, place of residence in a high-incidence indigenous community, recent contact with a known tuberculosis (TB) case and/or a positive tuberculin skin test (TST)/interferon gamma release assay (IGRA) or a history of TB that was inadequately treated or with no record of treatment.

IPer the Canadian Tuberculosis Standards, 7th Edition.

**Low risk=combined normal haemoglobin; leucocytosis and anaemia; leucocytosis. High risk=combined normal haemoglobin; normal/low leucocyte count and anaemia; normal/low leucocyte count.

immigration medical surveillance) ${ }^{39}$ A limitation of this study includes the relatively small cohort, which is typical in low-incidence settings. A second limitation includes the retrospective study design, which affects the interpretation of the strength of relationship between clinical features and outcomes, though collection of the data evaluated in this study is by protocol and we are confident in their accuracy.

This study describes infectious TB cases in a highincome, low-incidence country where the disease is increasingly uncommon. We anticipate this description will contribute to the prompt submission of specimens for 


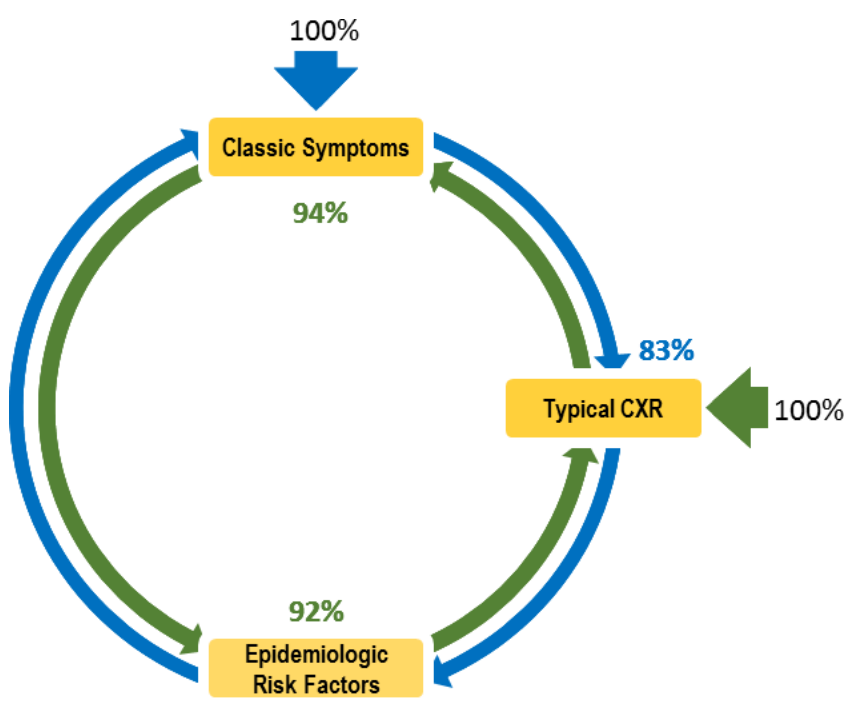

$95 \%$

Figure 1 Smear-positive pulmonary tuberculosis (TB) cases with typical chest radiographs. This figure describes a diagnostic loop with two entry points: (1) report of one or more classical pulmonary tuberculosis symptoms, and (2) report of a chest radiograph abnormality consistent with adult-type pulmonary tuberculosis. Proceeding clockwise, the percentages describe the proportion of patients with one or more classical symptoms who had each of the other features shown; proceeding counterclockwise the percentages describe the proportion of patients who had a chest radiograph abnormality consistent with adult-type pulmonary tuberculosis with each of the other features. CXR, chest X-ray.

confirmation by mycobacteriological testing. The prompt recognition of these cases is possible but takes a collaborative effort that includes front-line providers. Such input is understood to be a high-income, low-incidence country effort to follow the WHO/Stop TB Partnership roadmap to engage all care providers in TB prevention and care. ${ }^{11}$ Limiting the potential for transmission will ultimately aid TB elimination efforts. Electronic recording of the readily available clinical features proposed in this work along with computer-aided detection of adult-type PTB on chest radiographs could conceivably automate this process.

Acknowledgements The authors are very grateful to the staff of the Edmonton TB Clinic, the Provincial TB Clinic and the Tuberculosis Program Evaluation and Research Unit for assistance in assembling the data presented in this study.

Contributors $\mathrm{CH}$ and $\mathrm{RL}$ conceived this study. $\mathrm{CH}$ analysed and interpreted the data and provided initial drafts. JB interpreted the radiographs and was involved in critical review. $A D$ and $A S$ provided assistance with statistical methods and critical reviews. MLE and CP abstracted and collated relevant clinical data and provided critical reviews. RL interpreted the chest radiographs and provided expert oversight and critical reviews for all the drafts.

Funding An Alberta Lung Association/Respiratory Health Strategic Clinical Health Network Studentship, and the University of Alberta Pulmonary Research Group award provided financial support to the lead author for her studies, of which this work represents one part.

Competing interests None declared.

Patient and public involvement Patients and/or the public were not involved in the design, or conduct, or reporting, or dissemination plans of this research.
Patient consent for publication Not required.

Provenance and peer review Not commissioned; externally peer reviewed.

Data availability statement Data are available upon reasonable request. All data are available upon reasonable request made to the corresponding author. Subsequent secondary analyses will be subject to appropriate REB approvals as necessary.

Open access This is an open access article distributed in accordance with the Creative Commons Attribution Non Commercial (CC BY-NC 4.0) license, which permits others to distribute, remix, adapt, build upon this work non-commercially, and license their derivative works on different terms, provided the original work is properly cited, appropriate credit is given, any changes made indicated, and the use is non-commercial. See: http://creativecommons.org/licenses/by-nc/4.0/.

ORCID iD

Courtney Heffernan http://orcid.org/0000-0003-1241-7201

\section{REFERENCES}

1 Behr MA, Warren SA, Salamon $\mathrm{H}$, et al. Transmission of Mycobacterium tuberculosis from patients smear-negative for acidfast bacilli. Lancet 1999;353:444-9.

2 Hernández-Garduño E, Cook V, Kunimoto D, et al. Transmission of tuberculosis from smear negative patients: a molecular epidemiology study. Thorax 2004;59:286-90.

3 Tostmann A, Kik SV, Kalisvaart NA, et al. Tuberculosis transmission by patients with smear-negative pulmonary tuberculosis in a large cohort in the Netherlands. Clin Infect Dis 2008;47:1135-42.

4 Lau A, Barrie J, Winter C, et al. Chest radiographic patterns and the transmission of tuberculosis: implications for automated systems. PLoS One 2016;11:e0154032.

5 Catanzaro A. Nosocomial tuberculosis. Am Rev Respir Dis 1982;125:559-62.

6 Bailey WC, Gerald LB, Kimerling ME, et al. Predictive model to identify positive tuberculosis skin test results during contact investigations. JAMA 2002;287:996-1002.

7 Golub JE, Bur S, Cronin WA, et al. Delayed tuberculosis diagnosis and tuberculosis transmission. Int J Tuberc Lung Dis 2006;10:24-30.

8 Long R. Making a timely diagnosis of pulmonary tuberculosis. Can Respir J 2015;22:317-21.

9 Long R, Heffernan C, Gao Z, et al. Do "virtual" and "outpatient" public health tuberculosis clinics perform Equally Well? A ProgramWide Evaluation in Alberta, Canada. PLoS One 2015;10:e0144784.

10 Heffernan C, Doroshenko A, Egedahl ML, et al. Predicting pulmonary tuberculosis in immigrants: a retrospective cohort study. ERJ Open Res 2018;4. doi:10.1183/23120541.00170-2017. [Epub ahead of print: 20 Apr 2018].

11 World Health Organization and STOP TB Partnership. PublicPrivate mix for TB prevention and care: a roadmap. WHO/CDS/ TB/2018.32. Geneva, Switzerland: WHO, 2018. http://www.who.int/ tb/publications/2018/ppmroadmap

12 Small PM, McClenny NB, Singh SP, et al. Molecular strain typing of Mycobacterium tuberculosis to confirm cross-contamination in the mycobacteriology laboratory and modification of procedures to minimize occurrence of false-positive cultures. J Clin Microbiol 1993;31:1677-82.

13 van't Hoog AH, Meme HK, Laserson KF, et al. Screening strategies for tuberculosis prevalence surveys: the value of chest radiography and symptoms. PLoS One 2012;7:e38691.

14 Wisnivesky JP, Kaplan J, Henschke C, et al. Evaluation of clinical parameters to predict Mycobacterium tuberculosis in inpatients. Arch Intern Med 2000;160:2471-6.

15 Samb B, Henzel D, Daley CL, et al. Methods for diagnosing tuberculosis among in-patients in eastern Africa whose sputum smears are negative. Int J Tuberc Lung Dis 1997;1:25-30.

16 Long R, Maycher B, Dhar A, et al. Pulmonary tuberculosis treated with directly observed therapy: serial changes in lung structure and function. Chest 1998;113:933-43.

17 The Canadian Lung Association and the Public Health Agency of Canada. The Canadian tuberculosis standards. 7th edn, 2013. http:// www.publichealth.gc.ca/tuberculosis

18 Morris CD. The radiography, haematology and biochemistry of pulmonary tuberculosis in the aged. Q J Med 1989;71:529-3.

19 Morris CD, Bird AR, Nell H. The haematological and biochemical changes in severe pulmonary tuberculosis. $Q \mathrm{~J}$ Med 1989;73:1151-9.

20 Long R, Asadi L, Heffernan C, et al. Is there a fundamental flaw in Canada's post-arrival immigrant surveillance system for tuberculosis? PLoS One 2019;14:e0212706. 
21 Falk A, O'Connor JB, Pratt PC, et al. Classification of pulmonary tuberculosis. In: Diagnostic standards and classification of tuberculosis. 12th edn. New York: National Tuberculosis and Respiratory Disease Association, 1969: 68-76.

22 Cohen J. Statistical power analysis for the behavioral sciences. 2nd edn. Hillside, NJ: Lawrence Erlbaum Associates, 1998.

23 Perez-Guzman C, Torres-Cruz A, Villarreal-Velarde $\mathrm{H}$, et al. Progressive age-related changes in pulmonary tuberculosis images and the effect of diabetes. Am J Respir Crit Care Med 2000;162:1738-40.

24 Chan $\mathrm{CH}$, Woo J, Or KK, et al. The effect of age on the presentation of patients with tuberculosis. Tuber Lung Dis 1995;76:290-4.

25 Cohen R, Muzaffar S, Capellan J, et al. The validity of classic symptoms and chest radiographic configuration in predicting pulmonary tuberculosis. Chest 1996;109:420-3.

26 Al-Tawfiq JA, Saadeh BM. Radiographic manifestations of culturepositive pulmonary tuberculosis: cavitary or non-cavitary? Int $J$ Tuberc Lung Dis 2009;13:367-70.

27 Toman K. Tuberculosis: case finding and chemotherapy: questions and answers. Geneva: World Health Organization, 1979.

28 Phoa L-L, Teleman MD, Wang Y-T, et al. Characteristics of patients with delayed diagnosis of infectious pulmonary tuberculosis. Respirology 2005;10:196-200.

29 Jones BE, Young SM, Antoniskis D, et al. Relationship of the manifestations of tuberculosis to CD4 cell counts in patients with human immunodeficiency virus infection. Am Rev Respir Dis 1993;148:1292-7.

30 Skogberg K, Ruutu P, Tukiainen P, et al. Effect of immunosuppressive therapy on the clinical presentation and outcome of tuberculosis. Clin Infect Dis 1993;17:1012-7.
31 Kiyan E, Kilicaslan Z, Gurgan M, et al. Clinical and radiographic features of pulmonary tuberculosis in nonAIDS immunocompromised patients. Int J Tuberc Lung Dis 2003;7:764-70.

32 Wilcke JT, Askgaard DS, Nybo Jensen B, et al. Radiographic spectrum of adult pulmonary tuberculosis in a developed country. Respir Med 1998;92:493-7.

33 Lee H-S, Kee S-J, Shin J-H, et al. Xpert MTB/RIF assay as a substitute for smear microscopy in an intermediate-burden setting. Am J Respir Crit Care Med 2019;199:784-94.

34 Van Deun A, Tahseen S, Affolabi D, et al. Sputum smear microscopy in the Xpert ${ }^{\circledR}$ MTB/RIF era. Int $J$ Tuberc Lung Dis 2019;23:12-18.

35 Jones-López EC, Namugga O, Mumbowa F, et al. Cough aerosols of Mycobacterium tuberculosis predict new infection: a household contact study. Am J Respir Crit Care Med 2013;187:1007-15.

36 Banerii D, Andersen S. A sociological study of awareness of symptoms among persons with pulmonary tuberculosis. Bull World Health Organ 1963;29:665-83.

37 Styblo K, Dankova D, Drepela J, et al. Epidemiological and clinical study of tuberculosis in the district of Kalin, Czechoslovakia. Bull WHO 1967;37:819-74.

38 Shimao T. A study of the mode of detection of newly registered pulmonary tuberculosis patients with special reference to their symptoms. In: Reports on medical research problems of the Japan anti-tuberculosis association. , 1974: 21, 17.

39 Ward HA, Marciniuk DD, Pahwa P, et al. Extent of pulmonary tuberculosis in patients diagnosed by active compared to passive case finding. Int J Tuberc Lung Dis 2004;8:593-7. 